\title{
Comments on quiet daily variation derivation in "Identification of the IMF sector structure in near-real time by ground magnetic data" by Janzhura and Troshichev (2011)
}

\author{
P. Stauning \\ Danish Meteorological Institute, Lyngbyvej 100, 2100 Copenhagen, Denmark \\ Correspondence to: P. Stauning (pst@dmi.dk)
}

Received: 23 November 2012 - Revised: 6 June 2013 - Accepted: 18 June 2013 - Published: 16 July 2013

\begin{abstract}
The description presented in the paper of the relations of the solar wind sector structure to the derivation of the quiet daily variation (QDC) in polar magnetic recordings used for calculation of polar cap (PC) indices is found to be unclear and not properly justified. The presented example on inclusion of a solar sector term in an actual QDC series is found to be questionable even on the authors' premises.
\end{abstract}

Keywords. Magnetospheric physics (solar windmagnetosphere interactions)

\section{Introduction}

The above-mentioned paper, in which O. A. Troshichev (olegtro@aari.nw.ru) from the Arctic and Antarctic Research Institute (AARI) is the designated corresponding author, discusses the polar cap magnetic activity in relation to the conditions in the solar wind. There are many interesting analyses of the interplanetary magnetic field (IMF) structure and related polar magnetic variations in the paper. One further issue in the presentation is the relation of the solar wind sector (SS) structure to the derivation of the quiet day variation (QDC) for polar magnetic recordings. The QDCs are of considerable importance for the calculation of polar cap (PC) indices (Troshichev et al., 2006, 2007; Lukianova, 2007; Stauning et al., 2006; Janzhura and Troshichev, 2008; Stauning, 2011). However, it appears that there are unclear statements and problematic premises in the new paper. Since the PC index is expected to be put forward for the IAGA Assembly in 2013 for possible final acceptance, it is important that every feature of the index procedure is clearly defined and adequately substantiated. It is expected that the present commentary may help to reach this goal.

\section{Definition of solar sector effects on geospace activities}

The solar wind sector (SS) structure is usually defined in terms of whether the $B_{\mathrm{x}}$ component of the interplanetary magnetic field (IMF) is positive (toward the Sun) or negative (away). The solar wind that extends the coronal magnetic field has a spiral structure due to the solar rotation. Hence, at the Earth's position, the IMF $B_{\mathrm{y}}$ component is coupled to the embedded steady $B_{\mathrm{x}}$ component. Thus, the IMF $B_{\mathrm{y}}$ variations during enhancements in the IMF strength usually have a preferred polarity depending on the sector structure. It is well known that the solar sector structure affects all components of polar magnetic fields (e.g., Svalgaard, 1968). Usually, the IMF $B_{\mathrm{y}}$ component is considered the main responsible agent for SS effects in polar cap magnetic field variations at ground level.

\section{Inclusion of solar sector effects in QDC calculations}

The basic derivation procedure used at AARI for the quiet day variation (the QDC) in the geomagnetic components is defined in the publication by Janzhura and Troshichev (2008). The procedure defined there is in agreement with the concept stated on p. 2 of Troshichev et al. (2006) in their description of the unified PC index calculation from polar magnetic variations: "Magnetic deviations $\delta H$ and $\delta D$ are calculated from a certain level, 'curve of quiet day', which presents the daily magnetic variation, observed at the particular station during extremely quiescent days." However, in 
the above new publication (Janzhura and Troshichev, 2011), they state (p. 1491) that "One important detail in the procedure of the QDC derivation, which was not highlighted in Janzhura and Troshichev (2008) ... is a problem of allowance for sector structure effects."

Now, the new paper presents an interesting discussion of the SS effects and ways to identify the sector structure. However, concerning the QDC calculations it is not clearly described how, precisely, the SS effects are included. The statement (p. 1493) closest to such a definition is: "As a result of the DP2 current system modification, the daily variation of the polar cap magnetic activity changes, so that the daily level of activity at a certain station either increases or decreases, being dependent on the sign of the sector structure." Hence, the immediate question is - how, precisely, are the SS effects included in the QDC calculations?

A close inspection of the diagrams in their Figs. 1 and 7 may reveal the method. It seems that at first the daily QDCs for Thule are calculated using the method described in Janzhura and Troshichev (2008). They consider an interval of 30 days at a time. From this interval of data, a single day's QDC is derived. This date is determined as the weighted average of the dates involved and need not be the middle day of the interval. Then the interval is shifted forward by one day and the calculations repeated, which will define a QDC for the same or another day. When all QDCs possibly included in a 30-day interval have been derived, then they are processed by "two-dimensional bi-cubing interpolation with the subsequent Savitzky-Golay smoothing" (Janzhura and Troshichev, 2008) for the definition of a final QDC for each day. For online real-time applications, the QDCs are extrapolated to subsequent days, typically 15 days ahead.

The QDC for the first day of the 30-day interpolationsmoothing interval may need typically 15 days of data from the preceding interval. Correspondingly, the QDC for the last day of the present interval may need data from typically 15 days of the following interval. Hence each final QDC over a month needs data typically from an interval of $15+30+15=60$ days. The derived QDC amplitudes vary smoothly, which can easily be seen in Fig. 4 of Troshichev et al. (2011). Here, for the daily QDCs for the $H$ component at Vostok throughout November for the years 1997, 1998, 2000, 2001, 2002, and 2007, the amplitudes all vary almost linearly throughout the month (local summer) with absolutely no indication of any solar wind sector modulation.

Inspecting the QDCs for Thule displayed by the heavy line in Fig. 1 of the commented paper by Janzhura and Troshichev (2011) reveals the above-mentioned feature of an extremely smooth variation of the daily peak-to-peak amplitudes throughout the days from 145 to 245 of year 2001 shown in the figure. However, on top of the daily variation there is a longer term modulation shifting the QDC level up or down. Their Fig. 1 is attached to the present paper as Fig. A1.
An inspection of their Fig. 7 reveals a varying excursion of the smoothed daily median of the $H$ component values depicted by the asterisks. These excursions are displayed for the full year 2001 in their Fig. 4 and in more detail in Fig. 6 for June 2001, using the notation $\mathrm{SS}\left(H_{\mathrm{THL}}\right)$ for the quantity. It is seen in Fig. $6 \mathrm{~b}$ that the amplitude of the variation in smoothed $\mathrm{SS}\left(H_{\mathrm{THL}}\right)$ values in June is around $100 \mathrm{nT}$. The same amplitude variation is seen in the upper and lower edges of the $H$ component QDCs displayed in Fig. A1. Hence the modulated QDCs displayed by the heavy line in Fig. A1 are most likely obtained by imposing a shift corresponding to the values of the slowly varying $\mathrm{SS}\left(H_{\mathrm{THL}}\right)$ to all QDC values determined by the original Janzhura and Troshichev (2008) methods.

However, the modulation of the QDCs of Fig. A1 is inconsistent with the general statement in the paper (p. 1493) that the SS effects on the QDC are caused by sector structure variations in the IMF $B_{\mathrm{y}}$ component. The top level of the series of QDC curves in Fig. A1 refers to nighttime QDC values while the bottom level refers to midday values. Top and bottom values are displaced by the same amount. However, their Fig. 5 displays the mean daily variation in the Thule $H$ component throughout the summer months of 2001 for selected IMF $B_{\mathrm{y}}$ intervals: $B_{\mathrm{y}}<-3 \mathrm{nT},-2<B_{y}<2 \mathrm{nT}, B_{\mathrm{y}}>3 \mathrm{nT}$. It also demonstrates considerable differences between day and night IMF $B_{\mathrm{y}}$ effects. Their Fig. 5 is attached to the present paper as Fig. A2.

The middle curve in Fig. A2 displays in a fair approximation the average QDC for the summer interval considered. The upper and lower curves are not QDCs but indicate the effects of the IMF $B_{\mathrm{y}}$ component on the polar magnetic variations. It is clear here that for all local night hours $(\sim 00: 00$ to 12:00 UT) the IMF $B_{\mathrm{y}}$ variations have little or no effect. The $H$ component values at night remain at the same level for the three groups of IMF $B_{\mathrm{y}}$ values. During daytime hours ( $\sim 12: 00$ to 00:00 UT), the $H$ components vary considerably to display maximum IMF $B_{\mathrm{y}}$ effects at local midday (at around 16:00 UT).

Although Fig. A2 shows little variation in the average $H$ components between different $B_{\mathrm{y}}$ cases during night, it is apparent that there are considerable variations at night seen in Fig. A1 from the excursions in the upper envelope of the QDC $H$ component, which appear to be consistent with the excursions in the lower envelope around noon.

If the features in Fig. A2 are taken to the display in Fig. A1, then the possible SS IMF $B_{\mathrm{y}}$-related effects should not change the upper envelope of the QDCs (the local night values), whereas the lower envelope of the QDCs (the midday values) should show an IMF $B_{\mathrm{y}}$-related sector structure modulation, which could be quite large in summer. Accordingly, the constructed QDCs displayed in Fig. A1 are inconsistent with the variations displayed in Fig. 5. 


\section{Discussions}

It is fully acknowledged that the commented paper holds many interesting analyses of the relationships between polar cap magnetic variations and interplanetary conditions. However, the description of the IMF $B_{\mathrm{y}}$ solar sector effects on the QDC calculations is inadequate, and the effects appear to be nearly the same day and night rather than varying in LT as shown in their Fig. 5.

An important question is now how much the sector structure-related IMF $B_{\mathrm{y}}$ variations should affect the QDC reference level used in the calculation of PC index values. The authors tacitly assume that the filtered and smoothed curves in the $H$ and $D$ component plots in Fig. 3 represent quiet conditions and should be used as reference base levels for the PC index calculations. In my view they rather represent averages throughout quiet and disturbed conditions. For other indices derived from ground-based geomagnetic data, like K-indices, Dst, AL and AU indices, the reference levels are always defined from quiet conditions and not from the average levels throughout disturbed conditions. The same was true for the PC index according to Troshichev et al. (2006) in their definition of the index and also in Janzhura and Troshichev (2008) in their definition of the QDCs to be used in PC index derivation.

Furthermore, the way the IMF $B_{\mathrm{y}}$-related SS terms are applied to modify the QDCs may have substantial effects on the PC index values at local hours when the real IMF $B_{\mathrm{y}}$ effects are small or differ in their impact. The SS terms are derived from daily median values of the $H$ and $D$ components that after processing (cf. Fig. 6) provide correction terms $\Delta H_{\mathrm{y}}$ and $\Delta D_{\mathrm{y}}$. These correction terms have almost constant values during the day and are added to the corresponding steady QDC components, which in the PC index calculations are then subtracted from the measured magnetic variations. In order to derive their effects on the PC index, the correction terms should be projected to the optimum direction using the angle parameter, $\varphi$, and then divided by the slope, $\alpha$ (Troshichev et al., 2006, 2007).

Thus it is important that the derived SS terms correspond to the real IMF $B_{\mathrm{y}}$-related component changes during all hours of the day in order to give the proper contributions to the PC indices. However, it is clear from their Fig. 5 that the $\Delta H_{\mathrm{y}}$ correction term must have large variations during the hours of the day from near-zero at midnight to maximum at local noon (at around 16:00 UT). The similar statistics for the IMF $B_{\mathrm{y}}$-related $\Delta D_{\mathrm{y}}$ correction term (not shown) also indicates strong variations from night to day. Thus, the modifications of the QDC by the almost constant SS terms, $\Delta H_{\mathrm{y}}$ and $\Delta D_{\mathrm{y}}$, could be very different from the real IMF $B_{\mathrm{y}}$-related changes throughout day and night and could give substantial unaccounted changes in the PC index values.

The present commentary is not arguing that sector structure IMF $B_{\mathrm{y}}$ variations have no influence at all on the quiet level to be used in PC index calculations. The night level of the $H$ component is not affected significantly by the IMF $B_{\mathrm{y}}$ variations, but during the day there could be some effect on the QDC level for the $H$ component from systematic SS variations in the IMF $B_{\mathrm{y}}$ component. The argument here is that, in compliance with the definition of other geomagnetic indices, and also with the above-mentioned definition of the PC index in Troshichev et al. (2006), the reference QDC should be built from quiet segments only and should not include further contributions such as level shifts imposed by median or average values of the magnetic field made throughout all, quiet and disturbed, conditions. A suggestion of QDC calculations on these premises is presented in Stauning (2011).

\section{Conclusions}

The primary objective of the commented paper by Janzhura and Troshichev (2011) on identification of the IMF sector structure from ground magnetic data is well accomplished and interesting. Another issue presented in the paper is a new definition of the base level, the quiet day curve (QDC), used for deriving the disturbance geomagnetic variations to be used in polar cap (PC) index calculations.

The new definition includes a solar wind sector (SS) IMF $B_{\mathrm{y}}$-related term. The inclusion of this term is not adequately described and justified, and the resulting inclusion of a SS term in the QDC level is inconsistent even on the authors' own premises. The resulting QDCs for the $H$ component (their Fig. 1) display a strong SS IMF $B_{\mathrm{y}}$-related modulation in the level defined during local night in spite of the evidence presented (their Fig. 5) that the nighttime polar magnetic $H$ component values are not influenced much by IMF $B_{\mathrm{y}}$ variations.

Finally, the method used to apply the derived IMF $B_{y^{-}}$ related SS terms, which are almost constant throughout the day, to the QDC levels may have substantial unaccounted effects on the PC index values at local hours when the real IMF $B_{\mathrm{y}}$ effects on the QDC components are small or just different.

\section{Appendix A}

Below, reproductions are shown of the two important figures, Figs. 1 and 5, of the commented paper by Janzhura and Troshichev (2011). 


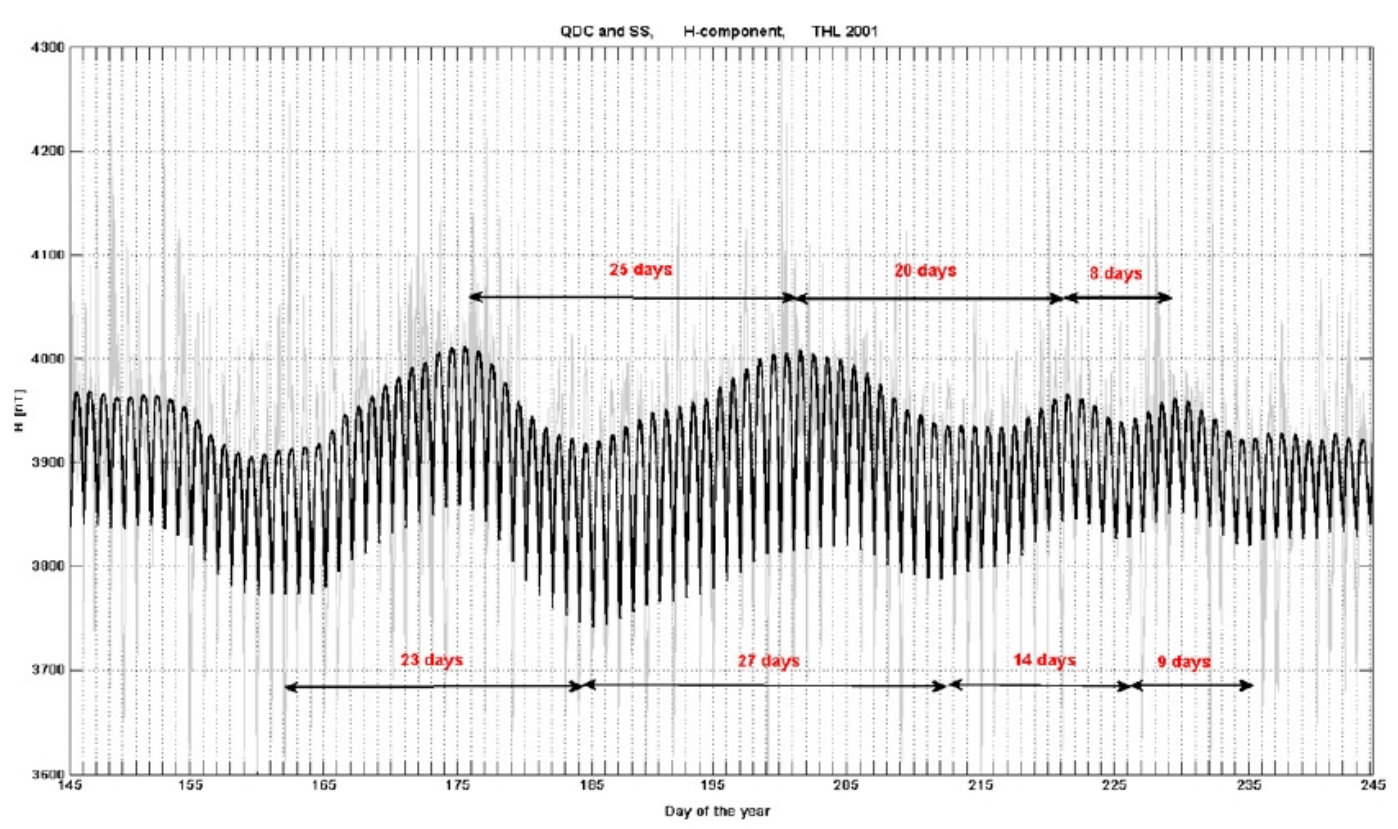

Fig. 1. Superposition of the actual variation of 1-min values of the geomagnetic H-component observed at Thule station in the summer season of 2001 (thin lines) and the quiet daily curve (QDC) characterizing the daily variation of the quiet geomagnetic field (thick solid lines).

Fig. A1. Figure 1 of Janzhura and Troshichev (2011). Superposition of the actual variation of 1 min values of the geomagnetic $H$ component observed at Thule station in the summer season of 2001 (thin lines) and the quiet daily curve (QDC) characterizing the daily variation of the quiet geomagnetic field (thick solid lines).
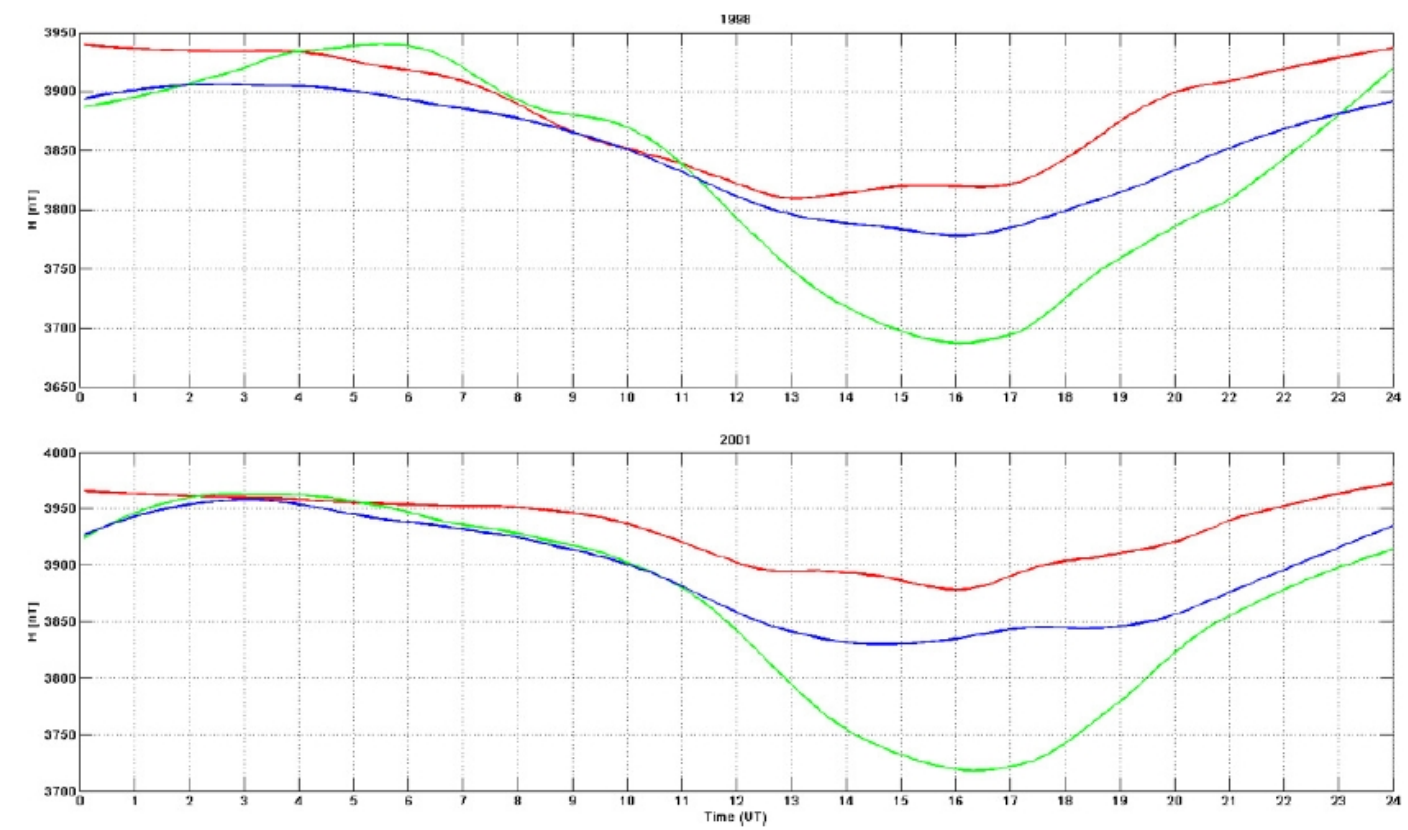

Fig. 5. The mean daily variation in $\mathrm{H}$ magnetic component at station Thule derived for three gradations of the IMF azimuthal component $B_{\mathrm{y}}>3 \mathrm{nT}$ (red line), $B_{\mathrm{y}}<-3 \mathrm{nT}$ (green line) and $-2<B_{\mathrm{y}}<2 \mathrm{nT}$ (blue line) for the summer months (May-August) of 1998 and 2001.

Fig. A2. Figure 5 of Janzhura and Troshichev (2011). The mean daily variation in $H$ magnetic component at station Thule derived for three gradations of the IMF azimuthal component $B_{\mathrm{y}}>3 \mathrm{nT}$ (red line), $B_{\mathrm{y}}<-3 \mathrm{nT}$ (green line) and $-2<B_{\mathrm{y}}<2$ nT (blue line) for the summer months (May-August) of 1998 and 2001. 
Acknowledgements. Topical Editor R. Nakamura thanks B. Emery for her help in evaluating this paper.

\section{References}

Janzhura, A. S. and Troshichev, O. A.: Determination of the running quiet daily geomagnetic variation, J. Atmos. Solar-Terr. Phys., 70, 962-972, doi:10.1016/j.jastp.2007.11.004, 2008.

Janzhura, A. S. and Troshichev, O. A.: Identification of the IMF sector structure in near-real time by ground magnetic data, Ann. Geophys., 29, 1491-1500, doi:10.5194/angeo-29-14912011, 2011.

Lukianova, R.: Comment on "The unified PCN and PCS indices: method of calculation, physical sense, dependence on the IMF azimuthal and northward components" by O. Troshichev, A. Janzhura, and P. Stauning, J. Geophys. Res., 112, A07204, doi:10.1029/2006JA011950, 2007.

Stauning, P.: Determination of the quiet daily geomagnetic variations for polar regions, J. Atm. Solar-Terr. Phys., 73, 2314-2330, doi:10.1016/j.jastp.2011.07.004, 2011.
Stauning, P., Troshichev, O., and Janzhura, A.: Polar Cap (PC) index. Unified PC-N (North) index procedures and quality. DMI Scientific Report, SR-06-04, available at www.dmi.dk/dmi/ sr06-04.pdf, 2006.

Svalgaard, L.: Sector structure of the interplanetary magnetic field and daily variation of the geomagnetic field at high latitudes, Danish Met. Inst. Geophys. Report R6, 1968.

Troshichev, O. A., Janzhura, A., and Stauning, P.: Unified PCN and PCS indices: method of calculation, physical sense and dependence on the IMF azimuthal and northward components, J. Geophys. Res., 111, A05208, doi:10.1029/2005JA011402, 2006.

Troshichev, O. A., Janzhura, A., and Stauning, P.: Reply to Comment of R. Lukianova on paper "The unified PCN and PCS indices: method of calculation, physical sense, dependence on the IMF azimuthal and northward components" by O. Troshichev, A. Janzhura, and P. Stauning, J. Geophys. Res., 112, A07205, doi:10.1029/2006JA012029, 2007.

Troshichev, O. A., Podorozhkina, N. A., and Janzhura, A. S.: Invariability of relationship between the polar cap magnetic activity and geoeffective interplanetary electric field, Ann. Geophys. 29, 1479-1489, doi:10.5194/angeo-29-1479-2011, 2011. 